\title{
A Slippery Slope of Authorship and Attribution: The Atelier Model and the Design/Build Conundrum
}

\author{
WILLIAM G. SARNECKY \\ American University of Sharjah
}

Focusing on the atelier model and design/build pedagogy, this paper explores the question of authorship and attribution in academia. While the legalities of copyright and authorship in architectural practice have been addressed legislatively and through adjudication, there is no analog to this clarification for academics. Defining authorship of creative work in academia often remains a murky question, particularly when students and instructors work together. This uncertainty poses a particular problem for academics in pursuit of tenure where academic and creative authorship remain the primary form of currency. Case studies of three design/build projects at different scales will shed light on the complicated relationship between teacher, student and the creative work emerging from the atelier model.

\section{INTRODUCTION}

While the legalities of copyright and authorship in architectural practice have been addressed legislatively and through adjudication, there is no analog to this clarification for academics operating in the gray area of creative work inhabiting the zone between traditional research and professional practice. Defining authorship in this gray zone often remains a murky question, particularly when students and instructors work together. This uncertainty poses a particular problem for academics in pursuit of tenure where academic and creative authorship remain the primary form of currency. Case studies of three published and premiated design/build projects shed light on the complicated relationship between teacher, student and the creative work emerging from the atelier model.

The complexity of this issue demands careful bracketing of the subject. Examined here is the question of how to define authorship for work that emerges from the atelier model and design/build pedagogy, particularly when that work is awarded or cited in popular, professional or academic publications. This is not a reflection on all research, scholarship and creative work, or on all types of citations.
Standards for establishing authorship within normative academic writing are a separate issue and usually well established. It is not unusual, for example, for academic journals to limit attribution to second co-author for students contributing to scholarly papers. ${ }^{1}$

\section{COPYRIGHT AND AUTHORSHIP IN PROFESSIONAL PRACTICE}

The question of authorship and attribution is not unique to academia, of course. Architects in practice have struggled with this issue given the significance of intellectual property within the profession and the difficulty of establishing provenance in a discipline predicated on appropriation and reconsideration of existing ideas. Surprisingly, legal protection of copyright for the architecture profession arrived two hundred years after Congress passed the U.S. Copyright Act in 1790. The passing of the Architectural Works Copyright Protection Act in 1990 and its attendant test for substantial similarity have provided relatively thin protection for architectural copyright. ${ }^{2}$

Nevertheless, copyright and authorship have been protected in high profile cases. Terry Gilliam directly copied Lebbeus Woods' drawing "Neo Mechanical Tower (upper) chamber" for a set design in the film 12 Monkeys. Woods sued and won a significant financial settlement. ${ }^{3}$ In Shine versus Childs, David Childs was accused of infringing the copyright of Thomas Shine, a Yale masters student, after attending his review and subsequently designing the Freedom Tower. The court found the designs were substantially similar and the case was resolved in $2006 .{ }^{4}$

Ana Miljački and Sarah Hirschman explored questions of copyright and authorship in their exhibition (Un)fair Use by providing examples of tropes or idioms that are fair territory for inspiration, and other examples of "unfair" moves presented through case studies of copyright infringement. ${ }^{5}$ All of these cases address the question of infringement external to an office or practice. There has been little legal need to clarify questions of authorship within a practice because most professional offices operate formally or informally under an atelier model. Conversely, the clear norms for attribution of authorship in the professional atelier model are equally unclear in academia. 


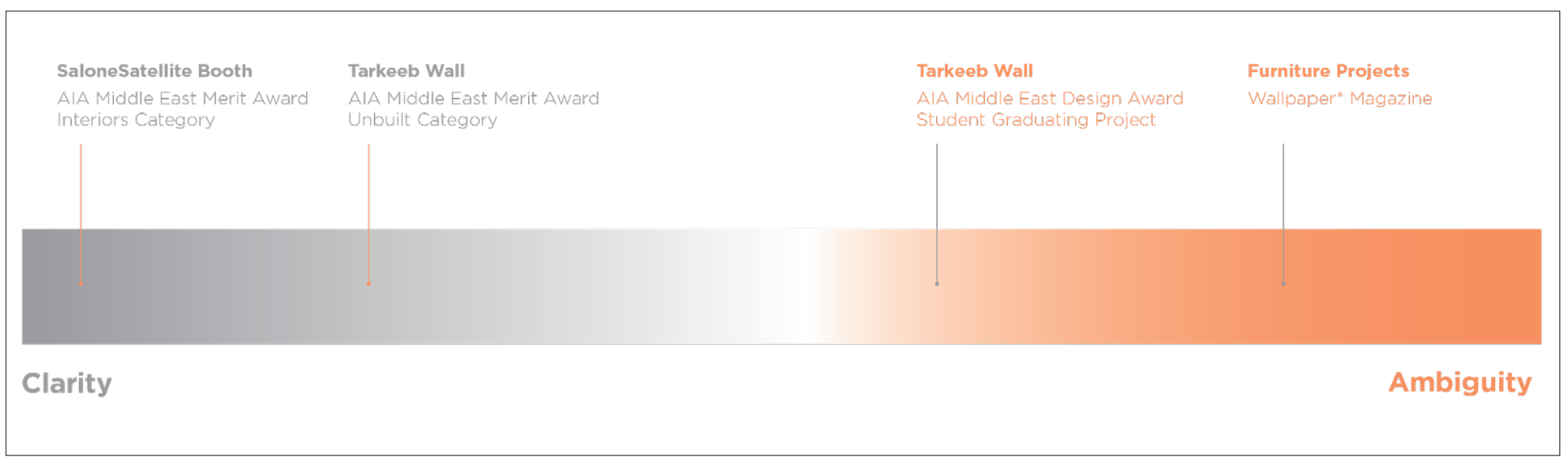

Figure 1: The Clarity/Ambiguity Spectrum for Authorship Attribution, with the case studies loosely positioned.

\section{THE ATELIER AND OTHER PEDAGOGICAL MODELS}

Defining three archetypal student/teacher relationships might help unravel the complex and ambiguous relationship between instructors, students and creative output. These archetypes include the mentor/critic model, the collaborative model and the atelier model. A self-directed student who enters a competition while seeking out mentorship from a trusted teacher best exemplifies the mentor/critic model. Authorship clearly remains with the student in this model. The collaborative model between teacher and student should be no differently considered than a professional collaboration (i.e. authorship is shared between collaborators).

Much of the potential ambiguity in authorship and attribution in academia emerges from the atelier model. Historically in an art atelier, a group of apprentices, students or assistants worked under the supervision of a master to complete a project in the master's name. Most architectural offices also follow some form of this atelier model. In either case, there is no ambiguity about authorship-it is credited to the master artist or the principal of the architecture office. This clear historical precedent does not always seem to apply within academia. At the very least, there can be confusion about how to deal with work produced in curricular or extracurricular contexts by students operating under an atelier model.

In Figure 2, it is difficult to distinguish between the work done by Faysal Tabbarah in his own practice, Architecture + Other Things and the work done by a student in his seminar course at the American University of Sharjah. When one looks at the work emerging from the teaching and the work emerging from the office, it's hard not to see the substantial similarity. This similarity is neither surprising, nor problematic. The seminar was taught using the atelier model where the instructor defines the mode and methodology of production. In a professional practice, authorship of the work would clearly be attributed to the head of the practice. Conversely, when an image of student work is published it is typically credited to the student. At times, the academic will be credited as the instructor or tutor.

The AD journal Exuberance: New Virtuosity in Contemporary Architecture, edited by Marjan Colletti, provides one example. Work emerging from an academic atelier model was published and the instructor, Hernan Diaz Alonzo, is credited as thesis advisor while the student, Steven Ma, is credited as author of the work. ${ }^{6}$ In this case, the instructor's work from his practice is also featured prominently in the same publication. Had that not been the case, work that in a professional setting would be credited to the head of the atelier would have been published with no credit to the academic. If this happens, should there be value given to the instructor's scholarly record where there is no attribution in print? How do academics distinguish between a student's work and the instructor's work when (as in this case) the provenance is so direct that the work can only have emerged from an atelier model led by the academic? And even more radically, should any distinction be made? In the end, it is up to the academic to sift through these murky waters based on the application of normative academic practices that don't align well with the atelier model.

\section{THE CLARITY/AMBIGUITY SPECTRUM FOR ATTRIBUTION OF AUTHORSHIP}

In many cases normative academic practices for attribution don't clearly apply to citations or awards involving the atelier model. Attribution for research and creative work emerging from the atelier model can land somewhere on a spectrum from a high level of clarity to a high level of ambiguity. The following case studies populate the full spectrum. Though the diagram in Figure implies a rational gradient along a single axis, a number of factors contribute to a more complex, multi-axial reality.

The first factor is curricular venue. Academics utilizing the atelier model find themselves working against a predisposition towards siloizing teaching and research or creative work. With the exception of scholarship about pedagogy, academics are predisposed to consider work done in a curricular venue as "teaching" rather than research, with creative output solely attributable the student. Under normative practice, an academic would not claim credit for creative work done within a course. There are exceptions to this generalization (for example design/build studios), but even these exceptions can be subject to their own ambiguities. In certain circumstances, normative academic practice allows for academics to take credit for creative work that engages students in an extra-curricular fashion.

Another factor that can impact clarity in attribution is the degree of instructor influence on a creative agenda. An atelier model by 


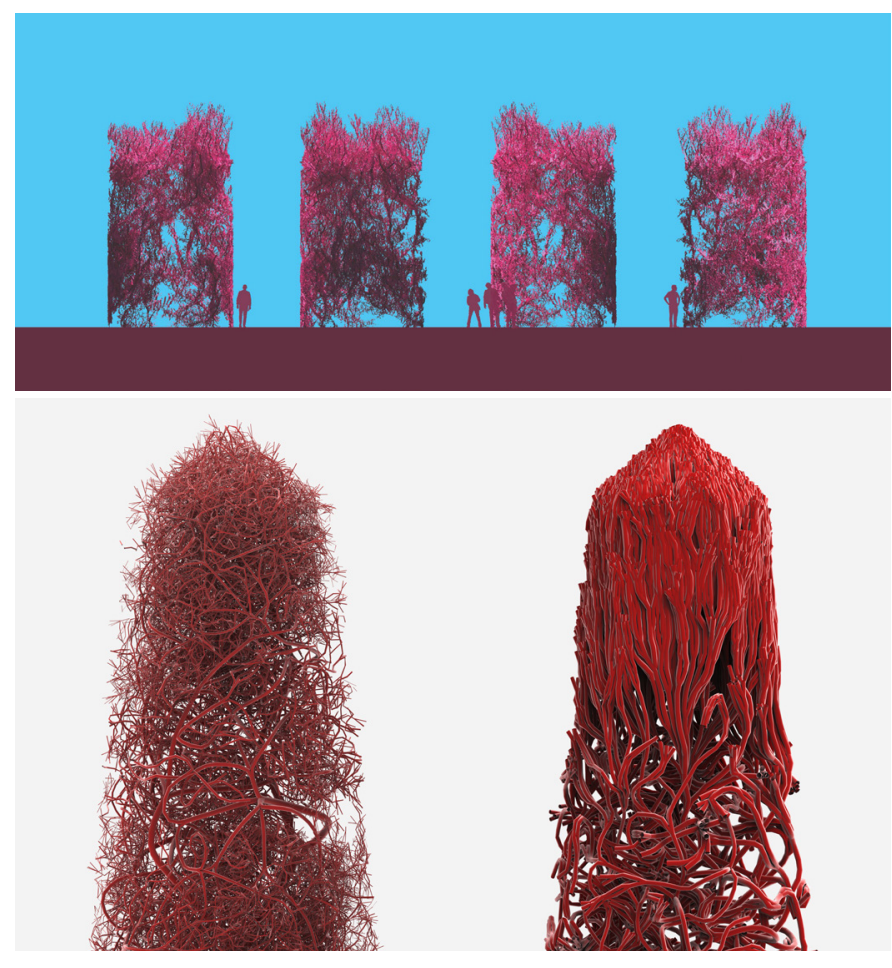

Figure 2: (top) The Primitive Hut Revisited Seminar, Student-Nasser Al Zayani, Instructor-Faysal Tabbarah; (bott) Atavistic Shelter, Faysal Tabbarah

its nature results in a strong instructor influence, a condition that is more viable in a topic studio or elective seminar than in a core studio or required course. Irrespective of venue, an atelier model emerges when an instructor exerts a high degree of influence on the subject and design methodology deployed in a design setting. In a professional environment, the head of the atelier would clearly claim attribution for work manifesting out of that setting. Academics producing work with this methodology struggle to attain this same level of attribution.

The number of students participating on a project also impacts attribution of authorship. Group projects more clearly fit within typical notions of the atelier model. Design/build studios with their inherently atelier model and group participation have several venues in which credit is given to the instructor. These venues include ACSA awards, as well as American Institute of Architects and other professional awards. This kind of attribution should not be limited to design/ build. Other examples, including atelier-model studios in which an instructor directs a winning entry to an open competition should be more directly and primarily attributable to the instructor. The curricular venue of the design studio can work against this attribution in normative academic practice.

Conversely, individual projects emerging from within an atelier context contribute to attributional ambiguity. For example, a group show of individual projects designed within an atelier condition leaves questions of how to attribute authorship and what role the instructor played. Adherence to professional practice of the atelier model would result in attribution of authorship to the head of the atelier (the instructor in this case) with credit given to the members of the team (the students in this case). Under normative academic practice, this group show tends to be treated as evidence of excellence in teaching for the instructor-obviously an important achievement, but less significant in the pursuit of tenure than credit for research and premiated creative work.

Finally, the context of citation or premiation influences attribution of authorship. Curricular work that wins a student competition or award appropriately would be attributed to the student submitting the work, regardless of whether that work was developed in an atelier model or not. In this case, instructors would typically be credited as the mentor or instructor. Conversely, authorship of atelier work that wins an open competition or a professional award or is published in a professional journal can be attributed to the instructor (while of course acknowledging student involvement).

\section{CASE STUDY 1-SALONESATELLITE EXHIBITION BOOTH}

The American University of Sharjah exhibition booth at SaloneSatellite provides a clear example of authorship and attribution (see Figure 3). In fall 2011, a graphic design and architecture instructor at AUS developed a cross-disciplinary course entitled Form, Furniture and Graphics. The following spring, AUS was invited to participate in the SaloneSatellite furniture exhibition in Milan. Four pieces from this course and four pieces from prior furniture courses taught by the architecture instructor were selected to represent AUS at the exhibition.

The architecture instructor designed and fabricated the parts of the booth that were shipped to Milan. To establish a link to the Form, Furniture and Graphics course, the design employed a base unit to create a wall pattern. A student in the Form, Furniture and Graphics class created the base unit during a preliminary 2-dimensional exercise.

In 2013, the project was premiated with a Merit Award in the Interiors category by AIA Middle East. In the submission, the architecture instructor claimed authorship of the project, while crediting the student for her pattern and the students who attended the SaloneSatellite exhibition for their help in assembling the booth. This project stakes a clear position on the clarity/ambiguity spectrum. Factors contributing to this clarity were the extra-curricular design and production venue, the lack of student involvement in the design phase of the project, the group of students participating in the assembly of the booth, as well as the venue of citation (a professional award).

\section{CASE STUDY 2-TARKEEB DESIGN/BUILD STUDIO}

The next case study began life as a one-semester design/build studio project in the fall of 2012. It provides an example of the slippery slope of attribution for premiation and citation of atelier model projects.

With the project less than halfway completed in the fall of 2013, it was submitted for an AIA Middle East award in the Unbuilt category. The jury awarded the unbuilt project with a Merit Award. Compared 

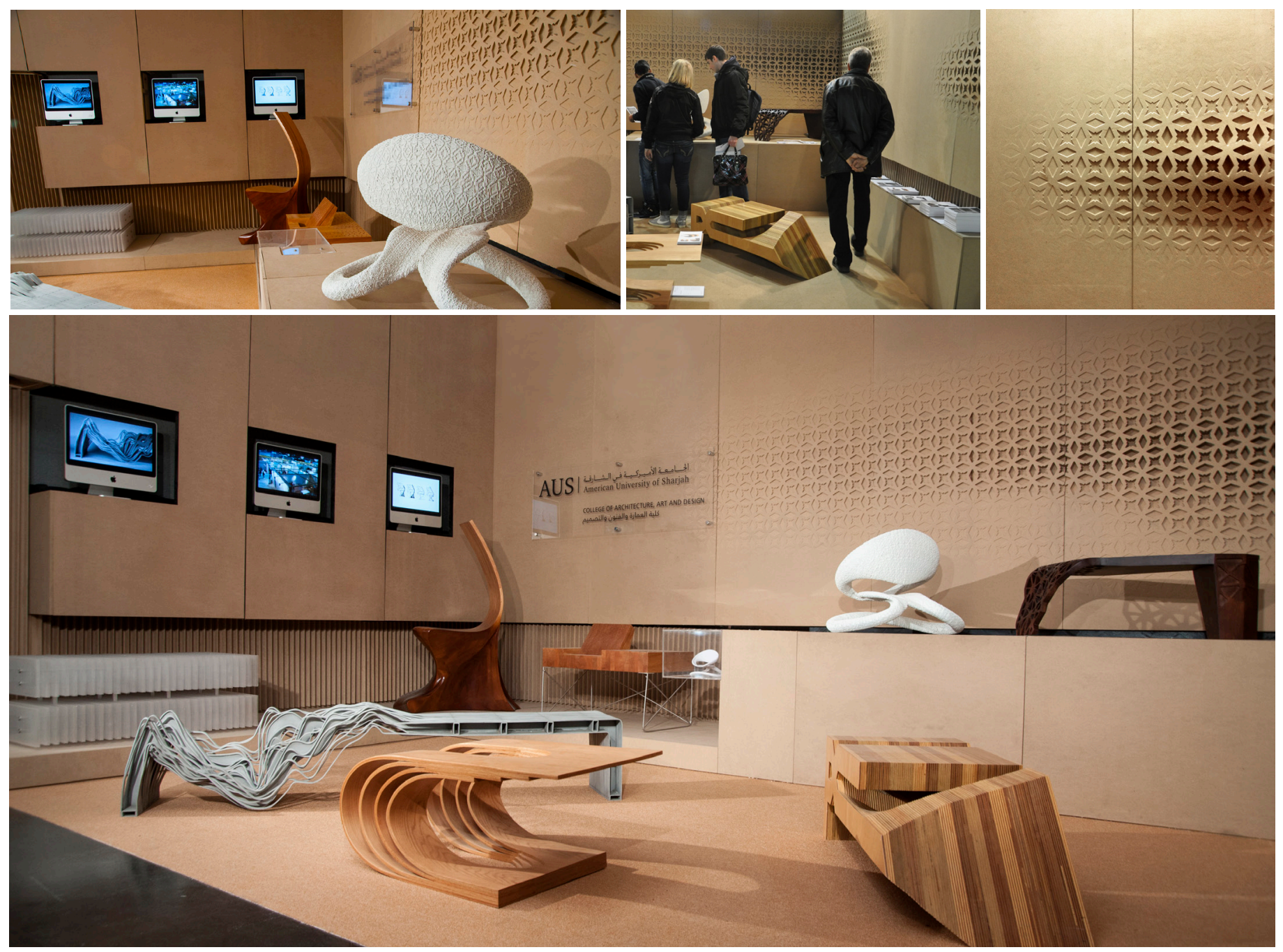

Figure 3: American University of Sharjah furniture exhibition booth at SaloneSatellite furniture fair in Milan, 2012, designed by William Sarnecky.

to the SaloneSatellite exhibition booth award, this premiation trends slightly in the direction of the ambiguous side of the authorship attribution spectrum. It is common practice to submit design/build projects for AIA awards under the instructor's name. However, the students in this case clearly were an indispensable part of the project design and fabrication team, contributing to some degree of ambiguity. Furthermore, a significant portion of the project was completed in curricular venues, unlike the booth project.

The students in the design/build studio graduated in the spring of 2013, leaving the instructor with the responsibility for finishing a project on which significant resources and time had already been expended. Over the course of the following two years and two separate advanced material fabrication courses, new students cycled into the project. The instructor also worked on the build in semesters when no course was associated with the project, including a sabbatical semester.

Upon completion, the project won another AIA Middle East award-this time the equivalent of an Honor Award (see Figure 4).
However, several factors contributed to a significant lack of clarity for attribution with this premiation of the project, moving it far into the ambiguous portion of the authorship attribution scale.

The project was submitted for an AIA Award in the Built Architecture category in fall 2015. That year, an inexperienced team administering the AIA awards unilaterally switched the project submitted under the instructor's name from the Built Architecture category to a newly created category for Student Graduating Projects. The jury, obliged to evaluate the submissions as provided by the administrators, awarded the project with the AIA Middle East's equivalent to an Honor Award in the Student Graduating Project category. The award certificate attributed the work to the American University of Sharjah with no mention of the submitting instructor's name.

These kinds of missteps and mistakes emerge from a misunderstanding of the atelier model within academia. The misunderstanding results in this logic stream: the project was designed in a curricular studio, so it must be student work, and therefore it must be placed in the student award category. The result is an award that is difficult for anybody, let alone the instructor, to claim credit. 


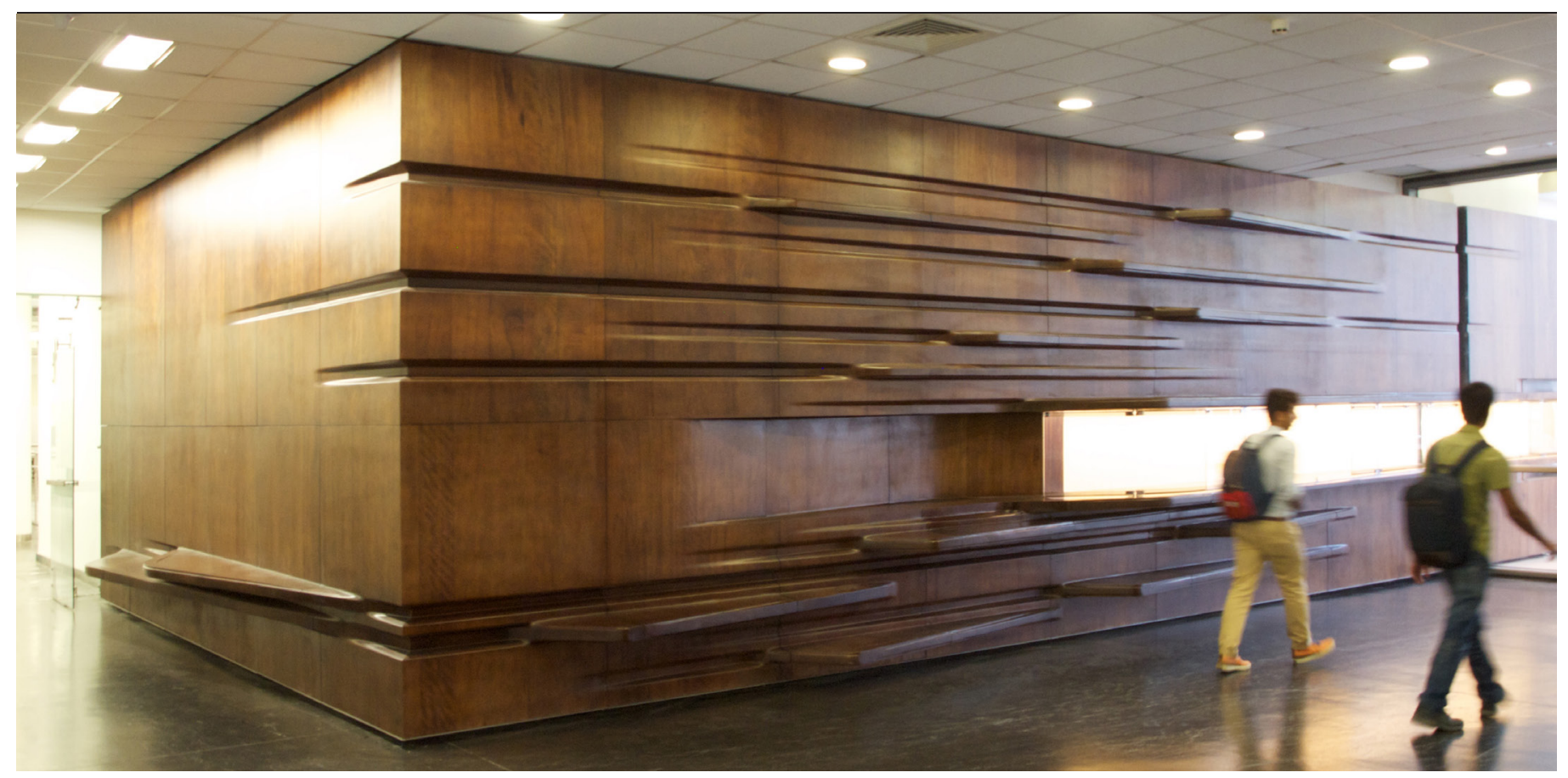

Figure 4: Interior portion of the AUS CAAD Display Wall by Tarkeeb Design/Build Studio
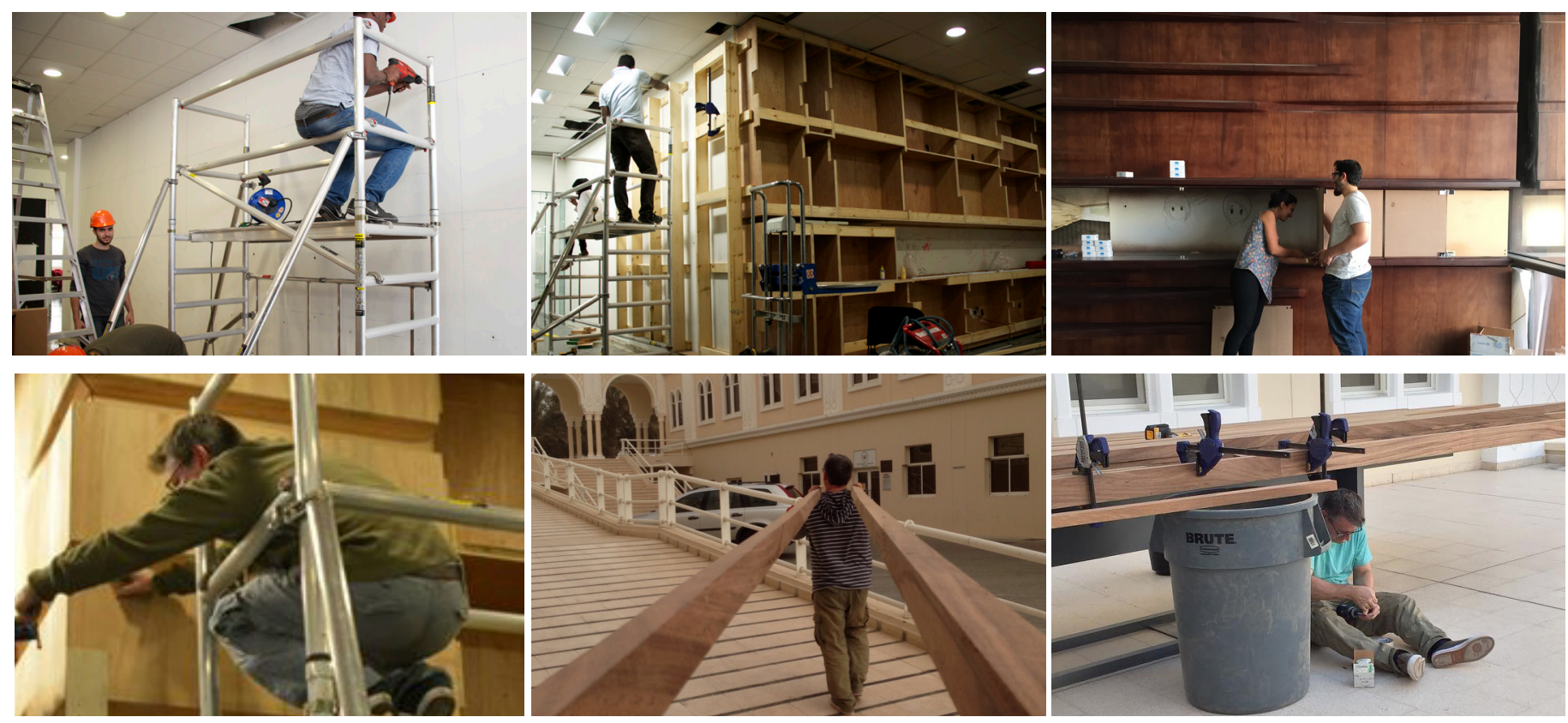

Figure 5: (top) Process images showing student participation in the Tarkeeb design/build; (bott) rarely shown process images of instructor involvement. 


\section{CASE STUDY 3-FURNITURE DESIGN AND WALLPAPER* MAGAZINE}

The final case study represents the most egregious example of an instructor's disenfranchisement from authorship credit and lands on the extremely ambiguous end of the authorship attribution spectrum. In 2014, Wallpaper* Magazine approached AUS because of the exhibition at SaloneSatellite. The magazine editor planned to do a series of photo shoots documenting the design scene from a number of countries for the Global Interiors issue. The editor selected three pieces from the SaloneSatellite exhibition to be included in a photo shoot in London. These projects comprised half of the pieces in the shoot representing the UAE. ${ }^{7}$

During the production process, the editor requested credits for the pieces. The instructor indicated the students should be credited, with the instructor listed as tutor and American University of Sharjah as the institution. The editor approved the credits, but for unknown reasons listed the students' names as well as the university in the magazine, but nowhere was the instructor credited.

Examining this case using the factors that influence clarity in attribution, all of the pieces were designed and fabricated under an atelier model with strong direction, leadership and participation of the instructor. The pieces were selected by an editorial body to represent the entire UAE (not the student population), and that representation consisted of multiple projects emerging from an atelier model. These factors should indicate an attribution of authorship to the instructor. Factors contributing to ambiguity were the design and fabrication in a curricular venue, and the fact that each furniture piece was an individual project within the atelier collective.

\section{CONCLUSION}

As in the case of the Tarkeeb design/build project and the 2015 AlA Award, the disenfranchisement of the instructor exhibited by the Wallpaper* citation emerges from a fundamental misunderstanding of the nature of the atelier model within academia. Perhaps an argument could be made for crediting a student and not the instructor had Wallpaper* selected only one student project to include in the UAE photo shoot. However the selection of multiple projects suggested that it was the work of the atelier led by the instructor being cited, as opposed to the work of a single, exceptional student.

And while these cases exhibit ambiguity and disenfranchisement in venues external to academia, academics themselves contribute to the problem. When presenting the design/build process, academics tend to exclusively show images of students working - that is to say, images depicting students fabricating the project while the instructor presumably benignly oversees the action. Academics almost never show process images with the instructor knee deep in the muck and the sawdust on the jobsite (see Figure 5). This fiction perpetuates the notion that these projects are student driven, even when they aren't. Perhaps academics diminish their involvement in and responsibility for projects because the notion of the atelier model in which the instructor is the leader (and often participant) of a team is not well understood, accepted or accounted for within normative pedagogical models.
This ambiguity leaves academics engaging the atelier model with a series of questions. Who controls attribution and authorship? Should an instructor using the atelier model be credited the same way as the professional atelier model? Does academic stature influence attribution? Should academics receive scholarly credit in situations where editorial ambiguity denies it? What can, or should academics be doing to address these questions and provide clarity for their colleagues utilizing the atelier model?

\section{ENDNOTES}

1. ACSA, "Author Guide" Journal of Architectural Education (February 2016): 05.

2. Margaret Rhodes, "Architecture's Fine Line Between Stealing and Inspiration," Wired, November 2, 2015, accessed July 24, 2016, http://www.wired.com/2015/10/ architectures-fine-line-stealing-inspiration.

3. Hans ten Cate, "Terry Gilliam, Universal, \& Architect Settle Copyright Dispute- "12 Monkeys" Not To Be Re-Edited," PythOnline's Daily Llama, June 10, 1996, accessed July 24, 2016, http://www.dailyllama.com/news/1996/Ilama040.html.

4. Jeffrey Brown, "Too Close For Comfort," Architecture Magazine (November 2007), July 24, 2016, http://www.architectmagazine.com/practice/ too-close-for-comfort o

5. Rhodes, "Architecture's Fine Line Between Stealing and Inspiration."

6. Marjan Colletti, ed., "Exuberance: New Virtuosity in Contemporary Architecture," Architectural Design 80 volume 2: 15, 70-77.

7. Benjamin Kempton and Leandro Farina, “UAE: Design Shapes Up, Plus Dubai's Creative Hub," Wallpaper* Magazine, April 2014. 